\title{
Instabilities of a Baroclinic Zonal Flow in the Presence of Surface Topography
}

\author{
By Shigeo Yoden and Hitoshi Mukougawa \\ Geophysical Institute, Kyoto University, Kyoto 606, Japan \\ (Manuscript received 28 May 1983, in revised form 24 September 1983)
}

\begin{abstract}
Stability properties of a baroclinic zonal flow in the presence of surface topography are investigated by using 2-layer and 20-layer, quasi-geostrophic, low-order models. The effect of the topography is approximately incorporated into the model by using a rather simple lower boundary condition. Compared with the conventional baroclinic instability analysis, the present analysis has two differences: Inclusion of (1) effect of surface topography and (2) perturbation of zonal components.

Two kinds of instabilities are obtained in both models. One is the modified baroclinic instability, which is essentially the conventional baroclinic instability. However, the growth rate, the phase speed and the vertical structure of the wave perturbation vary in time depending on the phase relation between the wave and the topography. The other is the topographic instability, in which the wave perturbation grows exponentially in time without phase propagation. In the 20-layer model the second modes of both instabilities, in which the perturbation has a nodal structure in vertical, are obtained in addition to the first modes similar to those obtained in the 2-layer model.

Except for the time-dependency, however, the structure and energetics are similar in both instabilities. The eddy energy is supplied by the baroclinic conversion from the available potential energy of the basic zonal flow. The conversion rate of kinetic energy by the surface topography is small compared with the baroclinic conversion.
\end{abstract}

\section{Introduction}

The instability of a baroclinic zonal flow with respect to large-scale disturbances has been extensively investigated since the pioneering works by Charney (1947) and Eady (1949).

Recently Charney and Straus (1980) examined the stability of a baroclinic flow in the presence of surface topography. They used a 2-layer, quasi-geostrophic, low-order (i.e., severely truncated spectral representation) model, and adopted an approximated lower boundary condition in the pressure coordinate system to include the effect of the topography. Two kinds of instabilities were obtained in their model: One is the 'orographic form-drag instability' by which the stationary disturbance grows and the other is the 'orographically modified, baroclinic instability' for traveling waves. In a frictionless and adiabatic case, both instabilities are also obtained for the basic states with and without stationary wave components (Yoden, 1983).

The stability problem with surface topography was first investigated by Charney and DeVore (1979). They examined the stability property of a barotropic flow over wavy topography using a low-order model. The basic state with a stationary wave is unstable when the zonal flow is superresonant (see the equation (26) in their paper). In such a case the disturbance grows without horizontal propagation of phase.

Roads (1982) examined the stability of the basic state with a stationary wave in multi-layer, low-order models with realistic zonal wind profiles. For intermediate wavenumbers the equivalent barotropic structure is present in the multilayer models like that in the 2-layer model of Charney and Straus (1980). Similar stability properties of the basic state are also obtained. For the low wavenumbers, on the other hand, there are major differences between the models in the resonant responses and the stability 
properties due to the difference in the vertical resolution of the models.

Another approach to the topographic instability problem in the 2-layer model was performed by Pedlosky (1981) with a weak nonlinear theory. He concluded that the resonant interaction of the free Rossby wave with the topography introduces a subcritical instability which draws on the potential energy of the basic zonal flow. There is not a short-wave cutoff and the small-scale topography requires only very weak vertical shear for the instability.

In these studies they paid their attention to the stability properties of the basic states. However, the structure and the behavior of perturbations have not been studied yet.

In this paper we make a stability analysis of a baroclinic zonal flow in the presence of the surface topography by using a 2-layer and a multi-layer, quasi-geostrophic, low-order models. Especially temporal variations of the structure and the energetics of perturbations are investigated in detail. In the present study, only the basic state of a baroclinic zonal flow without stationary waves is examined to understand the nature of two kinds of instabilities.

\section{Model description, linear eigenvalue problem and energy equations}

\subsection{Model description}

We consider quasi-geostrophic motion in a mid-latitude $\beta$-channel. It is assumed that the motion is frictionless and adiabatic. The finite difference approximations of the quasi-geostrophic equations corresponding to $N$-layer model

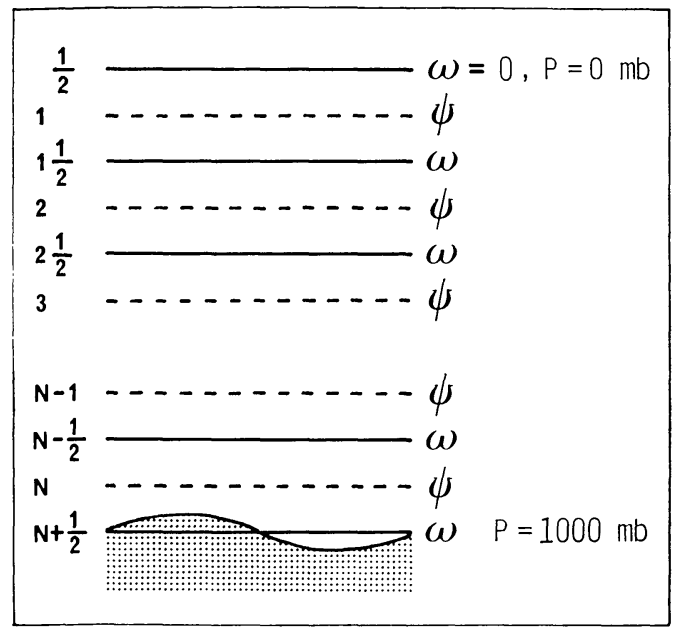

Fig. 1 A schematic representation of the $\mathrm{N}$ layer model.
(Fig. 1) become as follows: The vorticity equation applied to the level $l$ is

$$
\begin{aligned}
\frac{\partial}{\partial t} \nabla^{2} \psi^{l}+ & J\left(\phi^{l}, \nabla^{2} \phi^{l}+\beta y\right) \\
& =\frac{f_{0}}{\Delta p}\left(\omega^{l+1 / 2}-\omega^{l-1 / 2}\right), \\
& (l=1,2, \cdots, N) .
\end{aligned}
$$

The thermodynamic equation applied to the level $l+1 / 2$ is

$$
\begin{aligned}
\frac{\partial}{\partial t}\left(\phi^{l+1}-\phi^{l}\right)+ & J\left(\frac{1}{2}\left(\phi^{l+1}+\phi^{l}\right), \phi^{l+1}-\phi^{l}\right) \\
+ & \frac{S \Delta p}{f_{0}} \omega^{l+1 / 2}=0 \\
& (l=1,2, \cdots, N-1), \quad(2-2)
\end{aligned}
$$

where the following notations are used;

$t:$ time

$x:$ eastward coordinate

$y:$ northward coordinate

$p:$ pressure

$\nabla^{2}$ : horizontal Laplacian operator

$$
\left(=\frac{\partial^{2}}{\partial x^{2}}+\frac{\partial^{2}}{\partial y^{2}}\right)
$$

$J(a, b)$ : horizontal Jacobian operator

$$
\left(=\frac{\partial a}{\partial x} \frac{\partial b}{\partial y}-\frac{\partial a}{\partial y} \frac{\partial b}{\partial x}\right)
$$

$\phi^{l}(x, y, t)$ : geostrophic stream function at the level $l$

$\omega^{l+1 / 2}(x, y, t):$ vertical $p$-velocity at the level $l+1 / 2$

$f_{0}$ : Coriolis parameter at the center of the channel

$\beta$ : latitudinal variation of the Coriolis parameter

$\Delta p:$ pressure difference between the levels $l$ and $l+1$

$S:$ static stability parameter

Here the static stability $S$ is assumed to be constant in time and space.

Two rigid walls of the channel are placed at $y=0$ and $y=\pi L$, so the lateral boundary conditions are

$$
\begin{gathered}
\frac{\partial \phi^{l}}{\partial x}=0 \text { and } \frac{\partial}{\partial t}\left(-\left[\frac{\partial \phi^{l}}{\partial y}\right]\right)=0 \\
\text { at } y=0 \text { and } \pi L,
\end{gathered}
$$

where the square bracket denotes an average in $x$-direction.

In order to represent the effect of the surface topography, we adopt an approximated lower boundary condition as follows; 


$$
\omega^{N+1 / 2}=-\rho_{N} g J\left(\psi^{N}, h\right),
$$

where $\rho_{N}$ is the density of air at the level $N$, $g$ the gravitational acceleration, and $h(x, y)$ the topographic height. Here the hydrostatic and the quasi-geostrophic approximations are used and the topography is assumed to have a small amplitude. The validity of the use of $(2-4)$ is discussed in more detail in Appendix A.

The upper boundary condition is given by

$$
\omega^{1 / 2}=0 \text {. }
$$

Eliminating $\omega$ 's in (2-1) and (2-2) with (2-4) and (2-5), we obtain $N$ potential vorticity equations for $\phi$ 's as follows:

$$
\begin{aligned}
& \frac{\partial}{\partial t}\left\{\nabla^{2} \psi^{1}+\frac{1}{S}\left(\psi^{2}-\psi^{1}\right)\right\} \\
& +J\left(\phi^{1}, \nabla^{2} \phi^{1}+\beta y+\frac{1}{S} \psi^{2}\right)=0, \\
& \frac{\partial}{\partial t}\left\{\nabla^{2} \psi^{l}+\frac{1}{S}\left(\psi^{l+1}-2 \psi^{l}+\psi^{l-1}\right)\right\} \\
& +J\left(\phi^{l}, \nabla^{2} \phi^{l}+\beta y\right. \\
& \left.+\frac{1}{S}\left(\phi^{l+1}+\phi^{l-1}\right)\right)=0, \\
& (l=2,3, \cdots, N-1) \\
& \frac{\partial}{\partial t}\left\{\nabla^{2} \psi^{N}+\frac{1}{S}\left(-\psi^{N}+\phi^{N-1}\right)\right\} \\
& +J\left(\phi^{N}, \nabla^{2} \phi^{N}+\beta y\right. \\
& \left.+\frac{1}{S} \psi^{N-1}+h\right)=0,
\end{aligned}
$$

where all the variables and constants are nondimensionalized: $t$ is non-dimensionalized by $1 / f_{0}$; $x$ and $y$ by $L ; \phi^{l}$ by $L^{2} f_{0} ; \beta$ by $f_{0} / L ; S$ by $\left(L f_{0} / \Delta p\right)^{2}$; and $h$ by $\Delta p / \rho_{N} g$.

To simplify the problem, we expand $\phi^{l}(x$, $y, t)$ and $h(x, y)$ in orthogonal functions as in Charney and Straus (1980):

$$
\begin{aligned}
\left\{\begin{array}{l}
\phi^{l}(x, y, t) \\
h(x, y)
\end{array}\right\}= & \left\{\begin{array}{l}
\phi_{A}^{l}(t) \\
h_{A}
\end{array}\right\} F_{A}+\left\{\begin{array}{l}
\phi_{K}^{l}(t) \\
h_{K}
\end{array}\right\} F_{K} \\
& +\left\{\begin{array}{l}
\phi_{L}^{l}(t) \\
h_{L}
\end{array}\right\} F_{L},
\end{aligned}
$$

where

$$
\begin{aligned}
& F_{A}=\sqrt{2} \cos y, \\
& F_{K}=2 \sin y \cos n x, \\
& F_{L}=2 \sin y \sin n x,
\end{aligned}
$$

which satisfy the lateral boundary conditions (2-3).

Substituting the spectral expansion (2-7) into
(2-6), we finally obtain a set of $3 N$ ordinary differential equations for the expansion coefficients $\phi_{A}^{l}(t), \phi_{K}{ }^{l}(t)$ and $\phi_{L}{ }^{l}(t)(l=1,2, \cdots, N)$. The differential equations can be written symbolically as follows;

$$
\begin{aligned}
& \boldsymbol{B} \frac{d}{d t} \Psi=\boldsymbol{Q}(\Psi, \Psi)+\boldsymbol{L} \Psi, \\
& \Psi=\left(\phi_{A^{1}}, \phi_{K^{1}}, \phi_{L}{ }^{1}, \cdots, \phi_{A^{N}}, \phi_{K^{N}}, \phi_{L}{ }^{t}\right)^{t},
\end{aligned}
$$

where $B$ and $L$ are the coefficient matrices of the time derivative and linear terms of $\Psi$, respectively, and $\boldsymbol{Q}(\Psi, \Psi)$ the quadratic terms of $\Psi$ corresponding to the Jacobian terms. Full description of (2-9) is given in Appendix B.

\subsection{Linear eigenvalue problem}

If we set $d \Psi / d t=0$, a 'Hadley solution' with no wave is obtained as one of the steady solutions of (2-9): The Hadley solution is

$$
\begin{aligned}
& \phi_{A}^{l}: \text { arbitrary and } \phi_{A^{N}}=0, \\
& \phi_{K^{l}}=\phi_{L}{ }^{l}=0 \quad(l=1,2, \cdots, N) .
\end{aligned}
$$

There is no topographic effect in the Hadley solution, because there is no motion in the lowest layer $(N)$. Besides the Hadley solution there exist steady solutions with topographically forced waves as in the 2-layer models (Charney and Straus, 1980; Yoden, 1983) and in the multilayer model (Roads, 1982).

In this paper we investigate the linear stability of the Hadley solution with respect to small perturbations. Now we consider the initial evolution of the perturbed state, which is characterized by

$$
\Psi=\bar{\Psi}+\Psi^{\prime},
$$

where $\bar{\Psi}$ represents the basic state (i.e., the Hadley solution) and $\Psi^{\prime}$ the perturbation of the basic state. Substituting (2-11) into (2-9) and eliminating quadratic terms of $\Psi^{\prime}$, we obtain the linearized equations for $\Psi^{\prime}$ as follows:

$$
\boldsymbol{B} \frac{d}{d t} \Psi^{\prime}=[\bar{Q}(\bar{\Psi})+L] \Psi^{\prime},
$$

where $\bar{Q}(\bar{\Psi})$ is a matrix derived from the linearization of $Q(\Psi, \Psi)$.

If it is assumed that the perturbation $\Psi^{\prime}$ is given by

$$
\begin{aligned}
& \Psi^{\prime}=R_{e}\left[\Phi e^{\sigma t}\right], \\
& \Phi=\left(\phi_{A^{1}}, \phi_{K^{1}}, \phi_{L^{1}}, \cdots, \phi_{A^{N}}, \phi_{K}{ }^{N}, \phi_{L}{ }^{N},\right.
\end{aligned}
$$

a set of homogeneous linear algebraic equations for $\Phi$ is obtained from (2-12). From the necessary condition for the existence of non-trivial 
solutions, we can determine the eigenvalues $\sigma$ and the eigenfunctions $\Phi$ of the matrix $B^{-1}$ $[\bar{Q}(\bar{\Psi})+\boldsymbol{L}]$.

When $\sigma$ and $\Phi$ are obtained, the zonal component of the perturbation becomes as follows;

$$
R_{e}\left[\phi_{A} e^{\sigma t}\right] \cdot F_{A}=C \cos \left(\sigma_{i} t+\delta\right) e^{\sigma_{r} t} \cos y,
$$

where

and

$$
C=\sqrt{2}\left(\phi_{A r^{2}}+\phi_{A i}{ }^{2}\right)^{1 / 2}
$$

$$
\delta=\tan ^{-1}\left(\phi_{A i} / \phi_{A r}\right) \text {. }
$$

Here the superscript $l$ is omitted and the subscripts $r$ and $i$ denote the real and imaginary parts, respectively. The wave component of the perturbation is

$$
\begin{aligned}
R_{e}[ & \left.\phi_{K} e^{\sigma t}\right] \cdot F_{K}+R_{e}\left[\phi_{L} e^{\sigma t}\right] \cdot F_{L} \\
= & 2\left\{\left(\phi_{K r} \cos \sigma_{i} t-\phi_{K i} \sin \sigma_{i} t\right) \cos n x\right. \\
& \left.+\left(\phi_{L r} \cos \sigma_{i} t-\phi_{L i} \sin \sigma_{i} t\right) \sin n x\right\} e^{\sigma_{r} t} \\
& \times \sin y, \\
= & D(t) \cos (n x-\varepsilon(t)) e^{\sigma_{r} t} \cdot \sin y,
\end{aligned}
$$

where

$$
\begin{aligned}
D(t)= & 2\left[\left(\phi_{K r^{2}}+\phi_{L r^{2}}\right) \cos ^{2} \sigma_{i} t\right. \\
& -2\left(\phi_{K r} \phi_{K i}+\phi_{L r} \phi_{L i}\right) \cos \sigma_{i} t \sin \sigma_{i} t \\
& \left.+\left(\phi_{K i^{2}}+\phi_{L i}{ }^{2}\right) \sin ^{2} \sigma_{i} t\right]^{1 / 2}
\end{aligned}
$$

and

$$
\varepsilon(t)=\tan ^{-1}\left[\frac{\phi_{L r} \cos \sigma_{i} t-\phi_{L i} \sin \sigma_{i} t}{\phi_{K r} \cos \sigma_{i} t-\phi_{K i} \sin \sigma_{i} t}\right] .
$$

Therefore the phase speed of the wave is not generally constant in time. If and only if $\phi_{K}$ and $\phi_{L}$ satisfy the following relations

$$
\phi_{K r}= \pm \phi_{L i} \text { and } \phi_{K i}=\mp \phi_{L r},
$$

the wave has a constant phase velocity;

$$
\begin{aligned}
& \varepsilon(t)=\mp\left(\sigma_{i} t+\gamma\right) \text { and } \\
& D(t)=\left(\phi_{K r^{2}}+\phi_{L r}{ }^{2}\right)^{1 / 2}=\text { constant },
\end{aligned}
$$

where $\gamma=\tan ^{-1}\left(\phi_{K i} / \phi_{K r}\right)$.

Following Charney and Straus (1980), we classify the instability from the eigenvalues as follows:

$$
\left\{\begin{aligned}
& \sigma_{r}>0: \text { unstable } \\
& \sigma_{i}=0: \text { topographic instability }{ }^{\dagger} \\
& \sigma_{i} \neq 0: \text { modified baroclinic instability } \\
& \sigma_{r}=0: \text { neutral } \\
& \sigma_{r}<0: \text { stable }
\end{aligned}\right.
$$

$\dagger$ In this paper we use the term 'topographic instability' tentatively. As shown later, it does not always mean that the topography causes the instability.
In case of topographic instability the zonal flow component of the perturbation varies exponentially in time as $\exp \left(\sigma_{r} t\right)$ and the wave perturbation grows exponentially without phase propagation $\left(\varepsilon=\tan ^{-1}\left(\phi_{L r} / \phi_{K r}\right)\right)$. In case of modified baroclinic instability, on the other hand, the zonal component of the perturbation grows with oscillation.

\subsection{Energy equations}

Using the spectral representation (2-7), we define zonal kinetic energy $(K Z)$, eddy kinetic energy $(K E)$, zonal available potential energy $(A Z)$ and eddy available potential energy $(A E)$ as follows;

$$
\begin{aligned}
& K Z \equiv G \sum_{l=1}^{N}\left(\phi_{A}^{l}\right)^{2}, \\
& K E \equiv G \sum_{l=1}^{N}\left(n^{2}+1\right)\left\{\left(\phi_{K}^{l}\right)^{2}+\left(\phi_{L}^{l}\right)^{2}\right\}, \\
& A Z \equiv \frac{G}{S} \sum_{l=1}^{N-1}\left(\phi_{A}^{l+1}-\phi_{A}^{l}\right)^{2}, \\
& A E \equiv \frac{G}{S} \sum_{l=1}^{N-1}\left\{\left(\phi_{K}^{l+1}-\phi_{K}^{l}\right)^{2}+\left(\phi_{L}^{l+1}-\phi_{L}^{l}\right)^{2}\right\},
\end{aligned}
$$

where $G$ is a scaling factor in the dimensional form and $G=L^{2} f_{0}^{2} \Delta p /(2 g)$. From the nonlinear equation (2-9), it can be shown that $K Z, K E$, $A Z$ and $A E$ satisfy

$$
\frac{d}{d t}(K Z+K E+A Z+A E)=0 .
$$

Therefore the sum of the kinetic and the available potential energies is still conserved in the present low-order model.

If we consider the energetics of the linearized equations for the Hadley solution, each energy of $(2-18)-(2-21)$ becomes as follows;

$$
\begin{aligned}
& K Z=\overline{K Z}+K Z^{*}+K Z^{\prime} \\
& =G \sum_{l=1}^{N}\left\{\left(\bar{\psi}_{A}{ }^{l}\right)^{2}+2 \bar{\psi}_{A}{ }^{l}{\psi^{\prime}}{ }^{t}+\left({\psi^{\prime}}^{\prime}{ }^{l}\right)^{2}\right\}, \\
& K E=K E^{\prime}=G \sum_{l=1}^{N}\left(n^{2}+1\right)\left\{\left({\psi^{\prime}}^{\prime}{ }^{l}\right)^{2}+\left({\phi^{\prime}}_{L}{ }^{l}\right)^{2}\right\} \text {, } \\
& A Z=\overline{A Z}+A Z^{*}+A Z^{\prime} \\
& =\frac{G}{S} \sum_{l=1}^{N-1}\left\{\left(\bar{\psi}_{A}^{l+1}-\bar{\psi}_{A}\right)^{2}\right. \\
& +2\left(\bar{\psi}_{A}{ }^{l+1}-\bar{\psi}_{A}{ }^{l}\right)\left({\psi^{\prime}}_{A^{l+1}}-{\psi^{\prime}}{ }^{l}\right) \\
& \left.+\left(\phi^{\prime}{ }_{A}^{l+1}-{\psi^{\prime}}_{A}{ }^{l}\right)^{2}\right\} \text {, }
\end{aligned}
$$




$$
\begin{aligned}
A E=A E^{\prime \prime}= & \frac{G}{S} \sum_{l=1}^{N-1}\left\{\left({\phi^{\prime}}^{\prime}{ }^{l+1}-{\psi^{\prime}}^{\prime}{ }^{l}\right)^{2}\right. \\
& \left.+\left({\psi^{\prime}}^{\prime}{ }^{l+1}-{\psi^{\prime}}^{\prime}{ }^{l}\right)^{2}\right\},
\end{aligned}
$$

where an over bar denotes the basic state (the Hadley solution) and a prime denotes the perturbation. Because the zonal component of the perturbation is allowed, we must consider the cross terms between the basic state and the perturbation (i.e., $K Z^{*}$ and $A Z^{*}$ ). The time derivative of each energy becomes as follows;

$$
\begin{aligned}
& \frac{d}{d t} \overline{K Z}=\frac{d}{d t} \overline{A Z}=0, \\
& \frac{d}{d t} K Z^{*}=-\frac{d}{d t} A Z^{*}=C\left(A Z^{*}, K Z^{*}\right), \\
& \frac{d}{d t} K Z^{\prime}=C\left(A Z^{\prime}, K Z^{\prime}\right)-C B\left(K Z^{\prime}, K E^{\prime}\right),
\end{aligned}
$$

$$
\frac{d}{d t} K E^{\prime}=C\left(A E^{\prime}, K E^{\prime}\right)+C B\left(K Z^{\prime}, K E^{\prime}\right),
$$

$$
\begin{aligned}
& \frac{d}{d t} A Z^{\prime}=-C\left(A Z^{\prime}, K Z^{\prime}\right), \\
& \frac{d}{d t} A E^{\prime}=C\left(\overline{A Z}, A E^{\prime}\right)-C\left(A E^{\prime}, K E^{\prime}\right),
\end{aligned}
$$

where $C(A, B)$ denotes the -conversion rate from $A$ to $B$, and each conversion term is given in Appendix C. The energy diagram for the linearized equations of the Hadley solution is shown in Fig. 2. Note that the sum of $K Z^{*}$ and $A Z^{*}$ is conserved (see $(2-28)$ ), and that the energetics of the perturbation denoted by a prime is independent of these terms.

Because the perturbation is given by (2-13), each energy of the perturbation is divided into the part which varies in time with the period of $\pi / \sigma_{i}$ (oscillatory part) and the part which does not vary periodically (non-oscillatory part). For example, $K Z^{\prime}$ becomes

$$
\begin{aligned}
K Z^{\prime}= & G \sum_{l=1}^{N}\left[\left(\phi_{A r}\right)^{2}+\left(\phi_{A i}{ }^{l}\right)^{2}\right] \\
& \times\left\{\frac{1}{2}+\frac{1}{2} \cos 2\left(\sigma_{i} t+\delta^{l}\right)\right\} e^{2 \sigma_{r} t},
\end{aligned}
$$

where $\delta^{l}=\tan ^{-1}\left(\phi_{A i}{ }^{l} / \phi_{A r}{ }^{l}\right)$. The first term in the brace represents the non-oscillatory part and the second term the oscillatory part. When the perturbation is unstable, the non-oscillatory part grows monotonously in time as $\exp \left(2 \sigma_{r} t\right)$ and the growing oscillatory part is superimposed on the non-oscillatory part.

\section{Result in the 2-layer model}

The stability properties of the Hadley solution are investigated in the 2-layer model and in the 20-layer model. Most simplified system which can depict the baroclinic nature is the 2-layer model and the result is described in this section. The 20-layer model is used to give some generality to the result obtained in the 2-layer model. The result is described in the next section.

The parameter values used in this study are identical to those in Yoden (1983). The lateral boundaries are placed at $20^{\circ} \mathrm{N}$ and $70^{\circ} \mathrm{N}$. Therefore $L, f_{0}$ and $\beta$ with dimension are as follows;

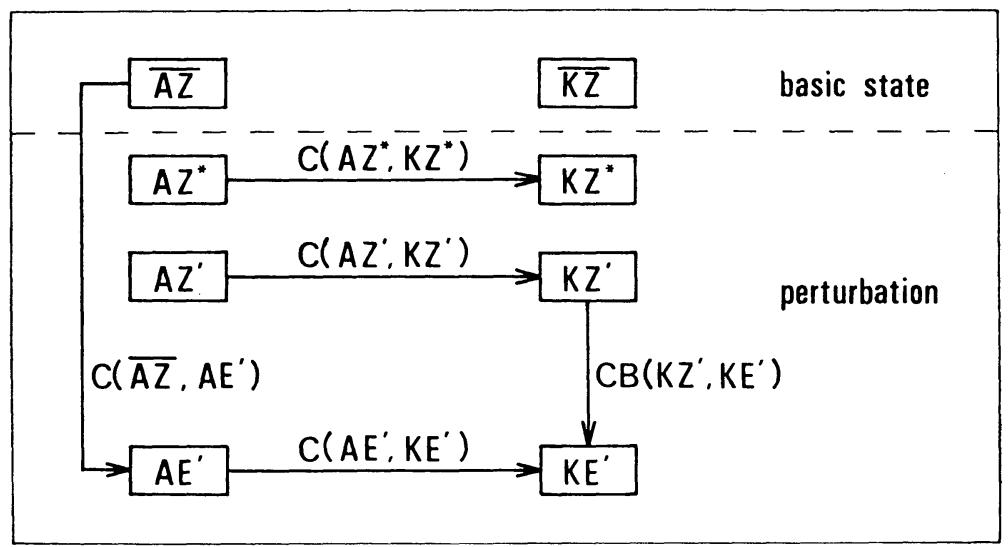

Fig. 2 Energy cycle diagram. The arrows indicate the positive direction of individual energy conversion processes as defined in Appendix C. 


$$
\begin{aligned}
& L=1.77 \times 10^{6} \mathrm{~m}, \\
& f_{0}=1.03 \times 10^{-4} \mathrm{~s}^{-1}, \\
& \beta=1.61 \times 10^{-11} \mathrm{~m}^{-1} \mathrm{~s}^{-1} .
\end{aligned}
$$

The static stability parameter $S=2.83 \times 10^{-2} \mathrm{~m}^{2}$ $\mathrm{s}^{-2} \mathrm{mb}^{-2}$ and this value corresponds to the vertical difference of potential temperature $30 \mathrm{~K}$ per $500 \mathrm{mb}$. The basic zonal flow of the Hadley solution is assumed to have a constant vertical shear $\Lambda=-\partial U / \partial p(U=-\partial \bar{\Psi} / \partial y)$. As a control parameter $\Lambda$ is varied from 0 to $7 \mathrm{~m} / \mathrm{s} / 100 \mathrm{mb}$. The surface topography is given by the cosine component $h_{K}\left(h_{A}=h_{L}=0\right)$ and the amplitude is varied from 0 to $1,500 \mathrm{~m}$.

\subsection{Parameter dependency}

In the 2-layer model the characteristic equation is as follows;

$$
\sigma^{2}\left(\sigma^{4}+a \sigma^{2}+b\right)=0,
$$

where the coefficients $a$ and $b$ are functions of the vertical shear, static stability, $\beta$-term, topographic height and wavenumber. This equation (3-2) is identical to the equation (3-9) in Charney and Straus (1980).

Depending on the signs of $a, b$ and $a^{2}-4 b$, four types of the eigenvalues are obtained (Fig. 3). Besides $\sigma=0, \sigma= \pm p i$ and $\pm q i$ in the neutral region; $\sigma= \pm p$ and $\pm q i$ in the topographic instability; $\sigma= \pm p$ and $\pm q$ in the double-topographic instability; and $\sigma=r \cdot \exp ( \pm i s)$ and $-r$. $\exp ( \pm i s)$ in the modified baroclinic instability. Here $p, q, r$ and $s$ are real and positive definites and $i$ the imaginary unit. Note that the region of modified baroclinic instability and the regions of topographic instability do not overlap because the degree of the characteristic equation is too low in the 2-layer model.

The stability diagram $\left(\Lambda-L_{x}\right.$ section) is shown in Fig. 4 for the topographic height $h=1,000 \mathrm{~m}$. The critical curves of the modified baroclinic and the topographic instabilities are obtained by solving the algebraic equations $a^{2}-4 b=0$ and $b=0$ for vertical shear. The topographic instability arises for longer wavelength and weaker vertical shear than the modified baroclinic instability. Note that the curve of long-wave limit of the topographic instability is independent of the topographic height $\left(\Lambda=3 \pi \beta / 8 \sqrt{2} n^{2}=(3 \beta)\right.$ $\left.32 \sqrt{2} \pi) L_{x}^{2}\right)$. The growth rates of both instabilities become large as the vertical shear increases. The Hadley solution is destabilized by the topography in short wavelengths. There does not exist the short-wave limit of both instabilities. It is noteworthy that a similar result was ob-

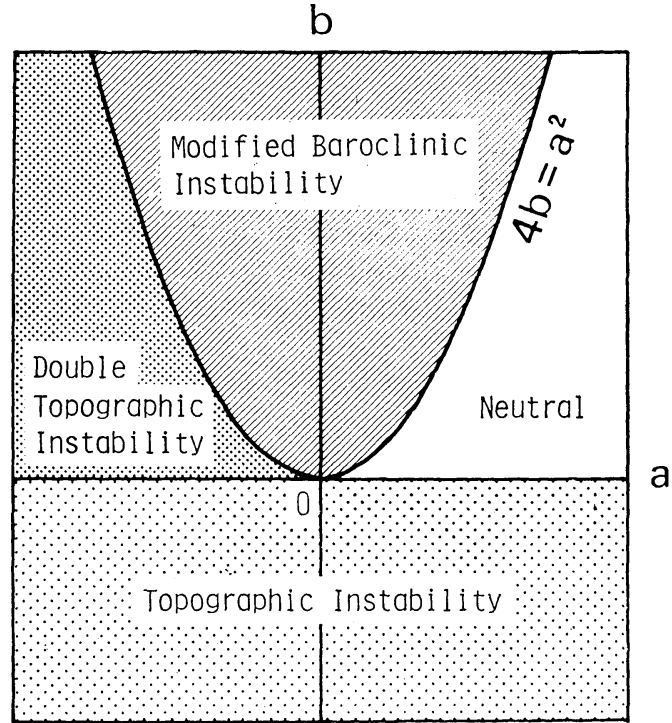

Fig. 3 Dependency of the types of instability on the coefficients $a$ and $b$, which depend on the vertical shear of the basic state, static stability, $\beta$-term, topographic height and wavenumber of the perturbation.

tained by a weak nonlinear theory (Pedlosky, 1981): There is not a short-wave cutoff and small-scale topography requires only very weak vertical shear for the instability.

The dependency on the topographic height is shown in Figs. 5. Here the vertical shear is fixed at $5 \mathrm{~m} / \mathrm{s} / 100 \mathrm{mb}$. The region of the doubletopographic instability exists when the topographic height is smaller than $700 \mathrm{~m}$. As the topographic height is increased, the region of the topographic instability becomes wide and the growth rate increases. On the other hand, the region of the modified baroclinic instability becomes narrow and the growth rate decreases with increasing the height. Note that there are two wavelengths from which the topographic and the double-topographic instabilities arise in the limit of $h=0 \mathrm{~m}\left(L_{x}=6,750 \mathrm{~km}\right.$ and $\left.7,200 \mathrm{~km}\right)$.

Real and imaginary parts of the eigenvalues are presented in Figs. 6 for four topographic heights $h=1,000 \mathrm{~m}, 300 \mathrm{~m}, 150 \mathrm{~m}$ and $0 \mathrm{~m}$. The real part $\left(\sigma_{r}\right)$ is the growth rate and the imaginary part divided by the wavenumber $\left(\sigma_{i} / n\right)$ is the mean phase speed of the perturbed wave over one wavelength of the topography. The eigenvalues of the double-topographic instability are continuously connected with those of the modified baroclinic instability or the topographic instability. The eigenvalue of the topographic 


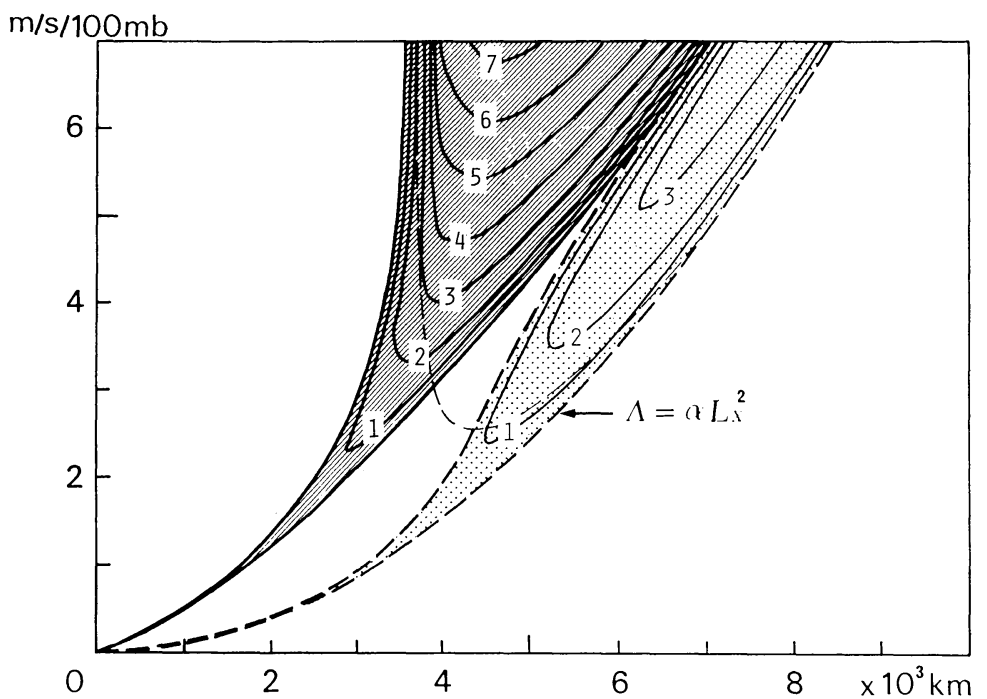

Fig. 4 Stability diagram in the 2-layer model $(h=1,000 \mathrm{~m})$. The abscissa indicates the wavelength and the ordinate the vertical wind shear. Heavy solid lines and heavy broken lines are the critical curves of the modified baroclinic instability and the topographic instability, respectively. A thin broken line indicates the critical curve of the baroclinic instability in case of no surface topography $(h=0 \mathrm{~m})$. The growth rate $\sigma_{r}$ is contoured by thin solid lines (multiplied by $10^{2}$ ). $\sigma_{r}=0.01$ corresponds to an $e$-folding time of 11.2 days.
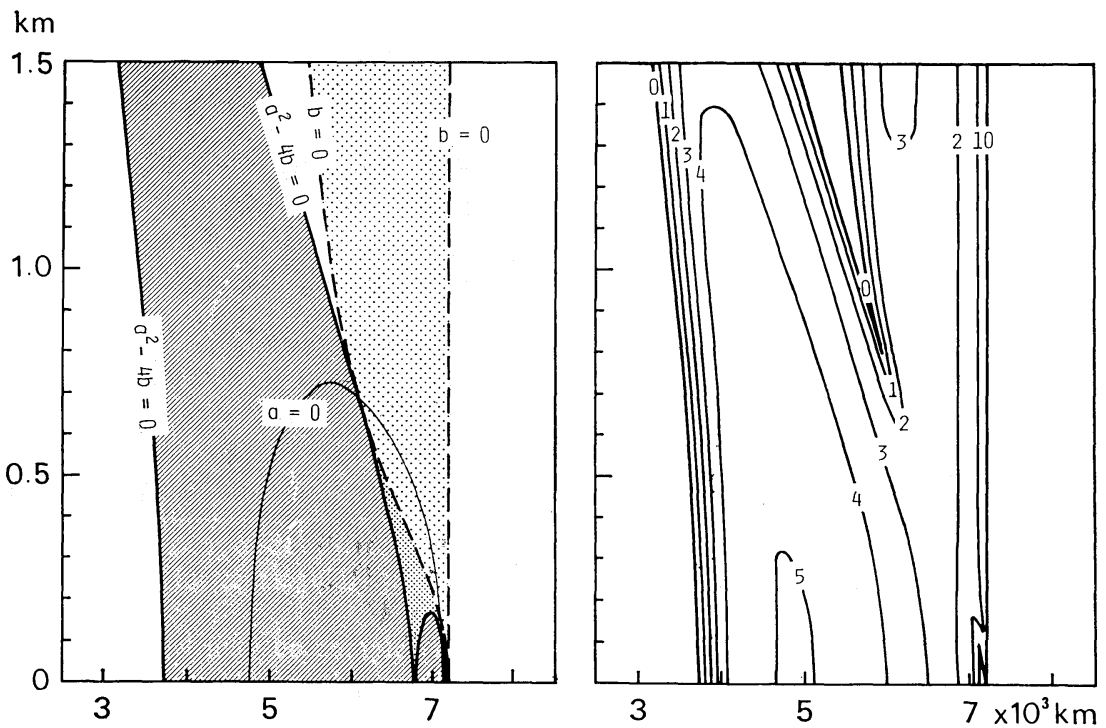

Fig. 5 Dependency of the instabilities on the topographic height $(\Lambda=$ $5 \mathrm{~m} / \mathrm{s} / 100 \mathrm{mb})$. The abscissa is the wavelength and the ordinate the topographic height. Left: Instability regions. The classification of each instability region is all the same as in Fig. 3. Right: The growth rate $\sigma_{r}$ multiplied by $10^{2}$. 

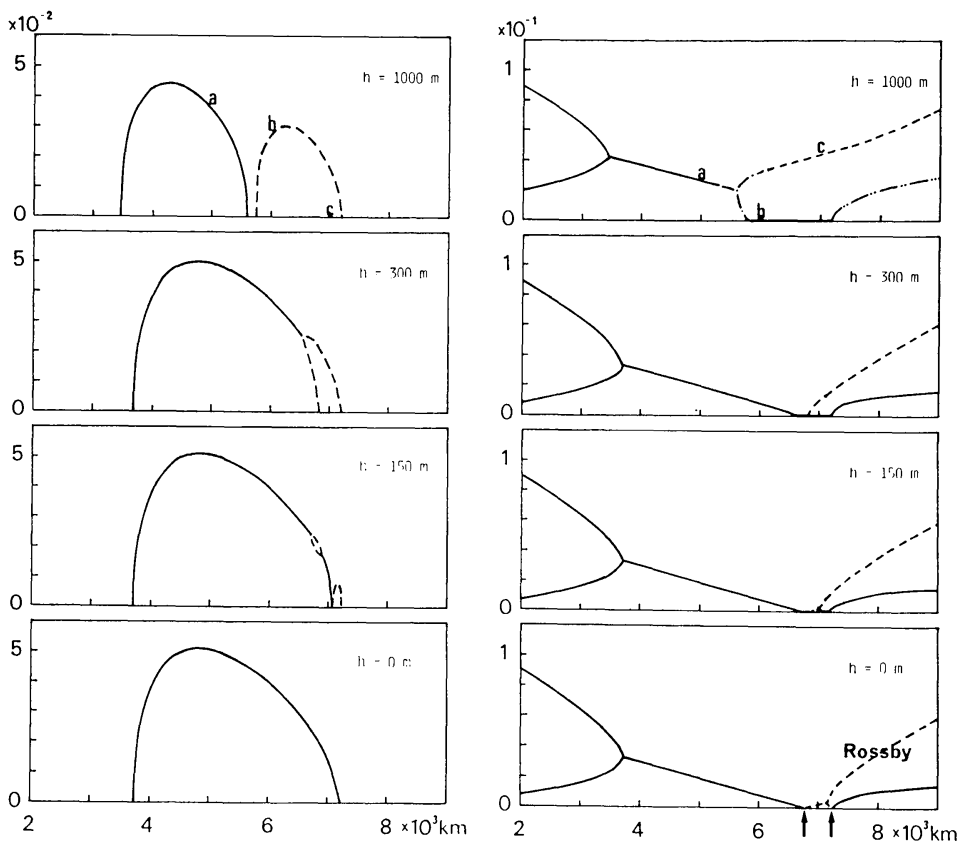

Fig. 6 Growth rate and mean phase speed for different four topographic heights $(\Lambda=5 \mathrm{~m} / \mathrm{s} / 100 \mathrm{mb})$. Left: The growth rate $\sigma_{r}$ for the unstable mode. Full and broken lines denote the (modified) baroclinic instability and the topographic instability, respectively. Right: The mean phase speed $\left|\sigma_{i} / n\right|$. Full and broken lines denote eastward and westward propagation in both layers, respectively. Dash-dotted line indicates eastward propagation in the upper layer and westward propagation in the lower layer. Dash-two dotted line indicates the opposite direction to that of dash-dotted line.

instability is also continuously connected with one of the double-topographic instability or that of neutral. From Figs. 5 and 6 , it is found that one of the onset of the topographic instability is the wavelength $\left(L_{x}=6,750 \mathrm{~km}\right)$ for which the baroclinically unstable wave becomes stationary and the other is the wavelength $\left(L_{x}=7,200 \mathrm{~km}\right)$ at which the neutral wave (which is not the Rossby wave type) becomes stationary.

In case of no topography, there is a difference compared with the baroclinic instability without horizontal shear in the 2-layer model: The perturbed wave becomes stationary at two wavelengths for the same vertical shear (denoted by arrows in Figs. 6). This is due to the effect of the horizontal shear of the zonal wind: The effective beta $\left(\beta-\partial^{2} U / \partial y^{2}\right)$ is increased (because $U=U_{0} \sin y$ ) and the phase velocity of the perturbed wave is decreased.

\subsection{Structure and energetics of perturbations}

In this subsection the time-variations of the structure and the energetics are described for one neutral and two types of unstable perturbations. Three cases denoted by (a)-(c) in Figs. 6 $(h=1,000 \mathrm{~m})$ are explained in order.

\section{(a) Modified baroclinic instability}

Time-variation of the perturbation is shown in Figs. 7. The zonal component of the perturbation grows with oscillation as described in (2-14). The oscillation is quite in phase in both layers and the amplitude is larger in the lower layer than in the upper layer. As also described in $(2-15)$, the vertical structure and the phase velocity of the wave perturbation change in time depending on the phase relation between the wave and the topography. When the trough in the upper layer is located nearly above the top or the bottom of the surface topography, the phase propagation slows down and the wave perturbation amplifies more rapidly.

Time-variations of each perturbation energy and its conversion rate are shown in Figs. 8 for 
the first half period in Figs. 7. The latter half relations of the time-variation is similar to the first half only multiplied by $\exp \left(2 \pi \sigma_{r} / \sigma_{i}\right)$. The growing oscillatory part is superimposed on the nonoscillatory part which grows monotonously in time as $\exp \left(2 \sigma_{r} t\right)$. The oscillatory part is more conspicuous in the kinetic energies, $K Z^{\prime}$ and $K E^{\prime}$. It is noteworthy that the magnitude of the conversion term by the surface topography $C B\left(K Z^{\prime}, K E^{\prime}\right)$ is less than those of the baroclinic conversions $C\left(\overline{A Z}, A E^{\prime}\right)$ and $C\left(A E^{\prime}, K E^{\prime}\right)$ all the time.

\section{(b) Topographic instability}

Because the eigenvalue $\sigma$ and the eigenfunction $\Phi$ are real in the topographic instability, the amplitudes of the zonal and wave perturbation vary in time as $\exp \left(\sigma_{r} t\right)$ and the phase of the wave is constant in time as $\varepsilon^{l}=\tan ^{-1}\left(\phi_{L r}{ }^{l}\right)$ $\left.\phi_{K r}{ }^{l}\right)$. The energy and its conversion terms have only non-oscillatory part. In order that each perturbation energy may continue to increase, the conversion terms must satisfy the following

$$
\text { and } \left.\begin{array}{l}
C B\left(K Z^{\prime}, K E^{\prime}\right)<C\left(A Z^{\prime}, K Z^{\prime}\right)<0 \\
-C B\left(K Z^{\prime}, K E^{\prime}\right)<C\left(A E^{\prime}, K E^{\prime}\right) \\
\\
\quad<C\left(\overline{A Z}, A E^{\prime}\right),
\end{array}\right\}
$$

which are obtained from (2-29)-(2-32) with setting the left hand side positive. Namely, the energy conversion due to the effect of surface topography must be the direction from $K E^{\prime}$ to $K Z^{\prime}$ in the topographic instability and the eddy kinetic energy $K E^{\prime}$ is supplied by the baroclinic conversion $C\left(A E^{\prime}, K E^{\prime}\right)$. The inequality $C B\left(K Z^{\prime}\right.$, $\left.K E^{\prime}\right)<0$ means that the ridge of the wave perturbation in the lower layer must be located in the lee side of the topography $\left(\psi^{\prime}{ }_{A}^{N} \times{\phi^{\prime}}_{L}{ }^{N}>0\right)$.

These considerations are indeed the case as is seen in Figs. 9 and 10 . The wave perturbation has a westward tilt of trough and ridge lines with height (about $\pi / 5$ between the two layers). The ridge of the wave in the lower layer is located in slightly east-side of the top of surface
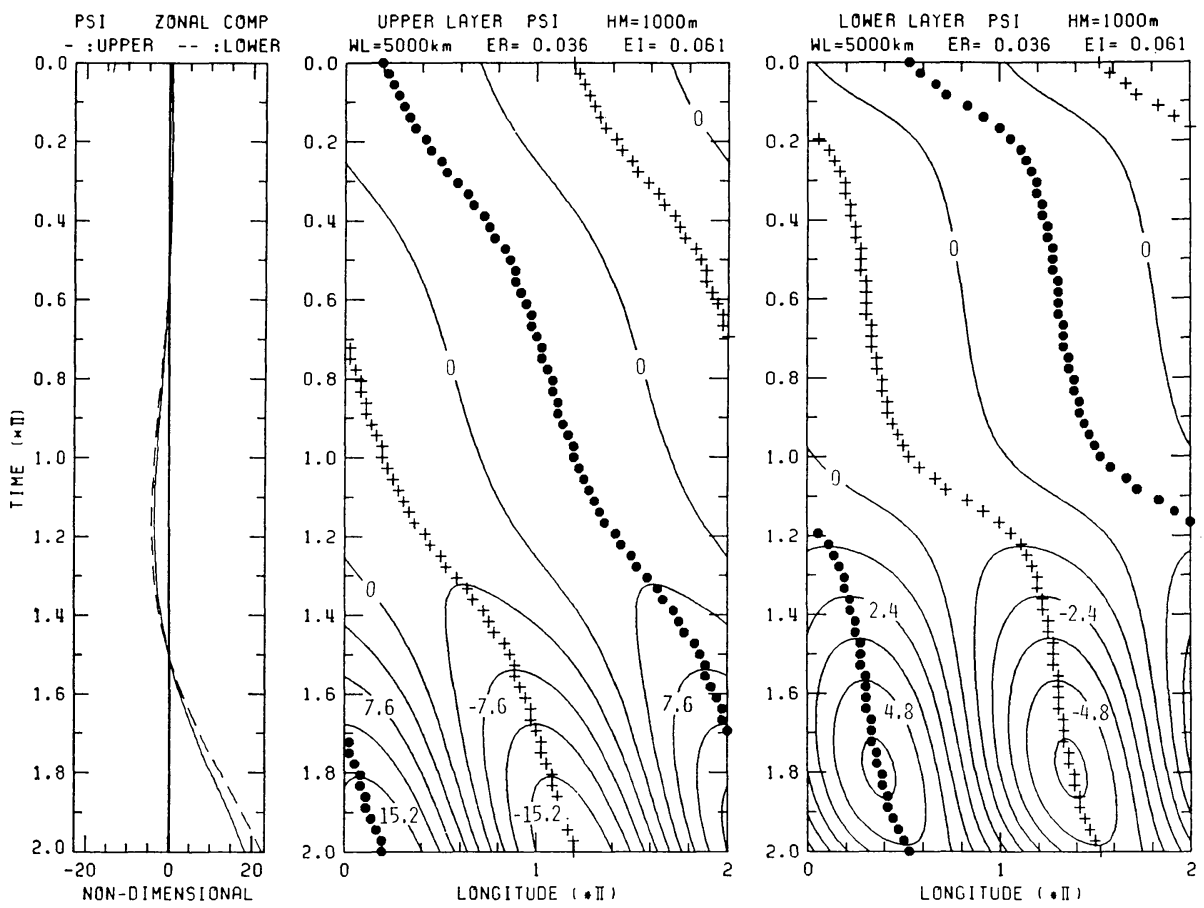

Fig. 7 Time-variation of the perturbation in the modified baroclinic instability $\left(\Lambda=5 \mathrm{~m} / \mathrm{s} / 100 \mathrm{mb}, L_{x}=5,000 \mathrm{~km}, h=1,000 \mathrm{~m}\right)$. Left: Time-variation of the zonal components in the upper (solid line) and lower (broken line) layers. Center: Time-longitude section of the wave perturbation in the upper layer. Trough and ridge are denoted by the symbols of + and $\bullet$, respectively. Right: Time-longitude section of the wave perturbation in the lower layer. The top of the topography is located at 0 and $2 \pi$ in the longitude. 

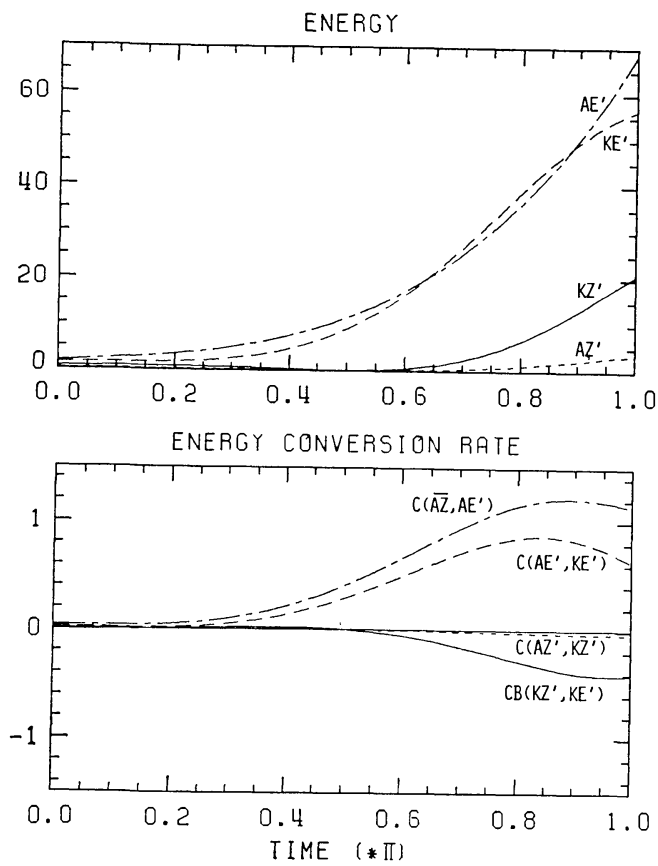

Fig. 8 Time variation of each perturbation energy (top) and its conversion rate (bottom) in the modified baroclinic instability $\Lambda=5 \mathrm{~m} / \mathrm{s} / 100 \mathrm{mb}, L_{x}=5,000 \mathrm{~km}, h=1,000$ $\mathrm{m})$. topography when the perturbation of the zonal flow is westerly.

\section{(c) Neutral wave}

As shown in Figs. 11, the amplitudes of the zonal and wave components of the neutral perturbation oscillate with the period of $2 \pi / \sigma_{i}$. The phase speed of the neutral wave is not constant and the vertical structure also varies in time periodically.

Figs. 12 show that the energy and its conversion terms vary in time with the half period of the zonal wind variation $\left(\pi / \sigma_{i}\right)$. All the energies have maximum values when the perturbation of the zonal flow has the maximum or minimum value. The conversion terms satisfy (3-3) when the perturbation energies are increasing, and vice versa.

Finally the non-oscillatory part of the energy conversion rates of the unstable perturbations is shown in Fig. 13 for all the unstable perturbations $(\Lambda=5 \mathrm{~m} / \mathrm{s} / 100 \mathrm{mb}$ and $h=1,000 \mathrm{~m})$. In both instabilities the non-oscillatory part satisfies the relation (3-3) and the baroclinic conversion is the source of eddy energy. Note that the eddy kinetic energy is supplied by the baroclinic
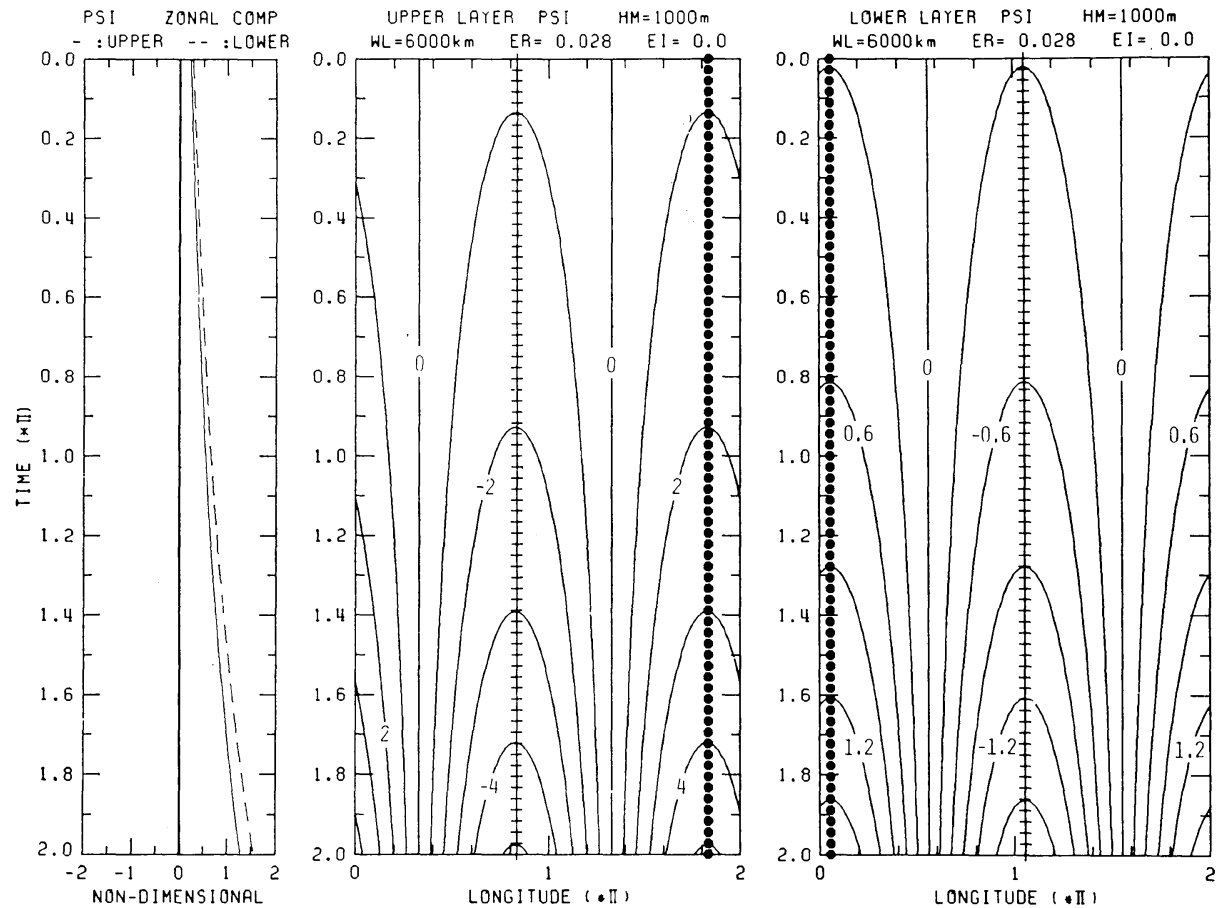

Fig. 9 As in Fig. 7 for the topographic instability $\left(\Lambda=5 \mathrm{~m} / \mathrm{s} / 100 \mathrm{mb}, L_{x}=\right.$ $6,000 \mathrm{~km}, h=1,000 \mathrm{~m})$. 

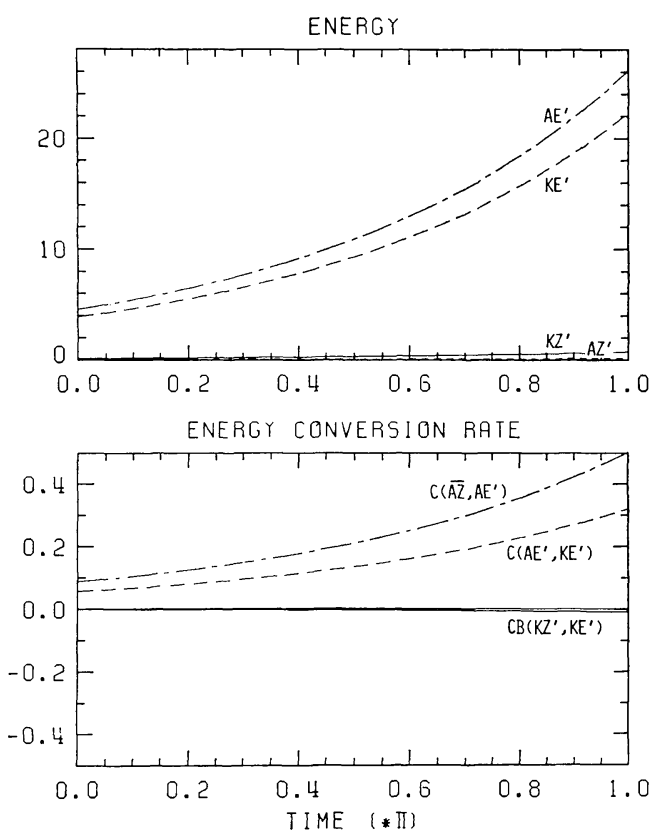

Fig. 10 As in Fig. 8 for the topographic instability $\left(\Lambda=5 \mathrm{~m} / \mathrm{s} / 100 \mathrm{mb}, L_{x}=6,000 \mathrm{~km}\right.$, $h=1,000 \mathrm{~m})$. conversion and that the conversion of kinetic energy by the surface topography is very small for all wavelengths.

\section{Result in the 20-layer model}

In order to remove some artificial constraints of the 2-layer model, we investigate the instability properties in the 20-layer model. With regard to the energetics of the perturbations, the relation (3-3) obtained in the previous section is valid in the present 20-layer model: The eddy energy is supplied by the baroclinic conversion for any kind of instabilities of the Hadley solution.

Both of the modified baroclinic and topographic instabilities are obtained in the 20-layer model with the topography $h=1,000 \mathrm{~m}$ (Figs. 14). The Hadley solution is unstable in almost all the wavelengths and the vertical shears. The second and the third modes of the modified baroclinic instability exist for the long wavelengths like as those of earlier studies by Green (1960) and Hirota (1968). The second mode of the topographic instability also exists for the long wavelength and small vertical shear.

Compared with the baroclinic instability with
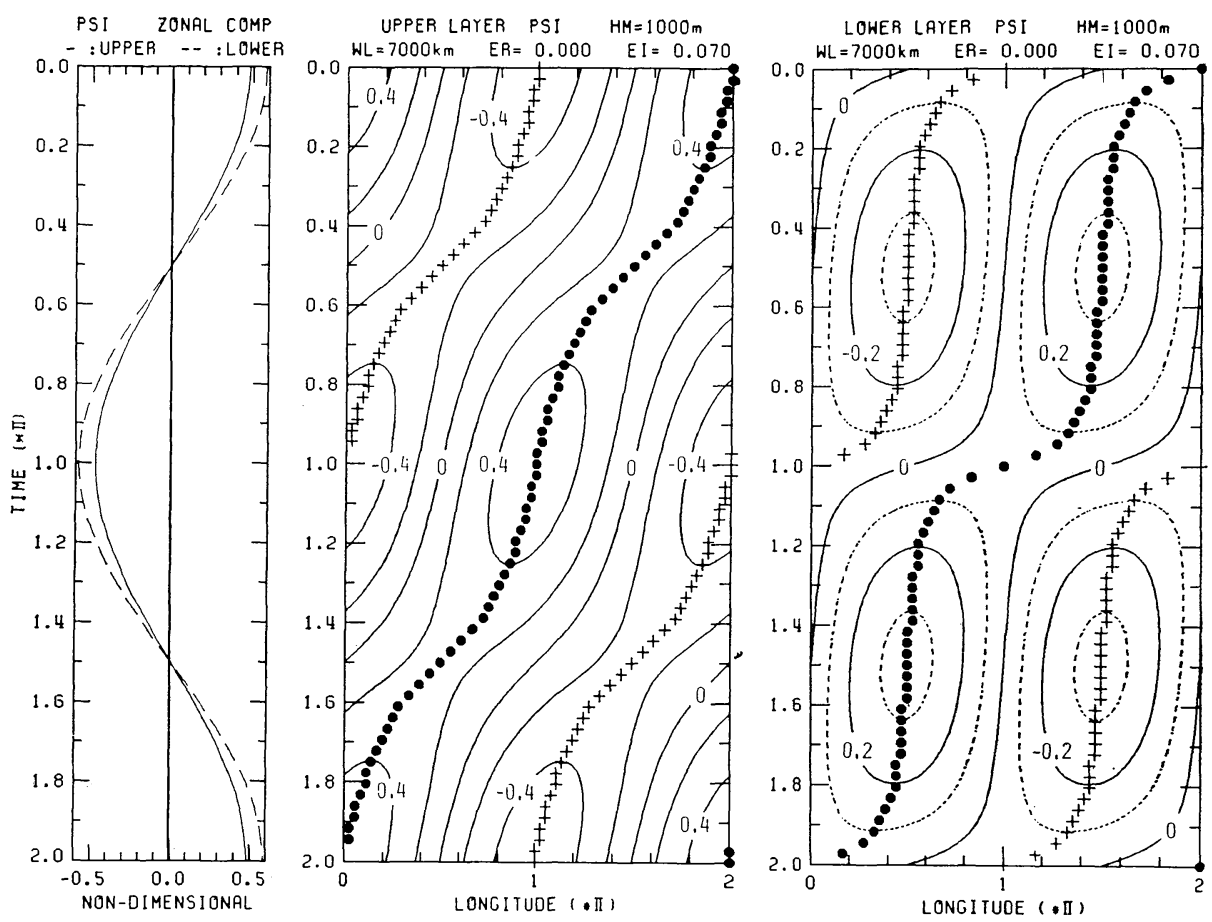

Fig. 11 As in Fig. 7 for the neutral perturbation $\left(\Lambda=5 \mathrm{~m} / \mathrm{s} / 100 \mathrm{mb}, L_{x}=\right.$ $7,000 \mathrm{~km}, h=1,000 \mathrm{~m})$. 

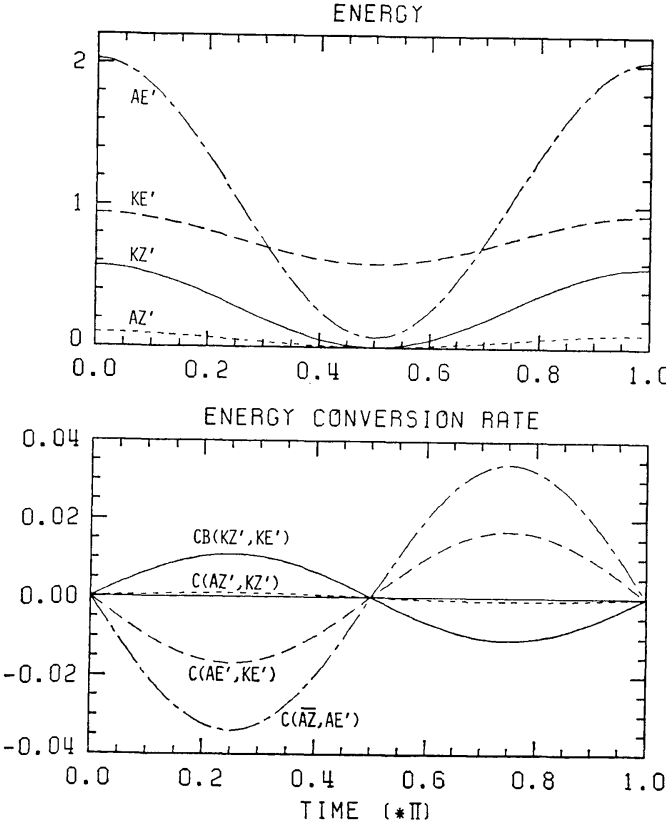

Fig. 12 As in Fig. 8 for the neutral perturbation $\left(\Lambda=5 \mathrm{~m} / \mathrm{s} / 100 \mathrm{mb}, L_{x}=7,000 \mathrm{~km}, h=\right.$ $1,000 \mathrm{~m})$.

no topography, it is found that the topographic instability arises in the neighborhood of the critical curves* of the baroclinic instability. The result about the onset of the topographic instability obtained in the 2-layer model is confirmed in the present 20-layer model: The topographic instability arises in the neighborhood of the wavelength for which the wave perturbation becomes stationary.*

The vertical structures of the perturbations in the topographic instability are presented in Figs. 15 for two modes denoted by $\boldsymbol{a}$ and $\boldsymbol{b}$ in Figs. 14. The first mode (a) has not a node of the amplitude of stream function and the position of the ridge is near the top of the surface topography in the westerly zonal flow perturbation in agreement with the result in the 2-layer model. On the other hand, the second mode (b) has a node near $p=600 \mathrm{mb}$ and the perturbation of stream function is nearly out of phase between the upper and lower layers.

Compared with the vertical structure of the baroclinically unstable perturbation in case of no topography (not shown), the resemblance of

* Hirota (1968) pointed out that the phase speed of the neutral Rossby wave becomes zero on the critical curve.

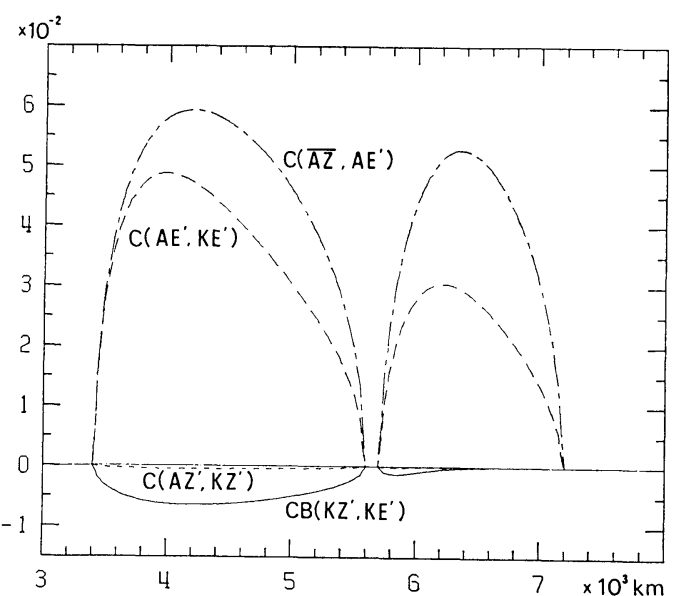

Fig. 13 Non-oscillatory part of the energy conversion rates of unstable perturbations $(\Lambda=$ $5 \mathrm{~m} / \mathrm{s} / 100 \mathrm{mb}, h=1,000 \mathrm{~m})$.
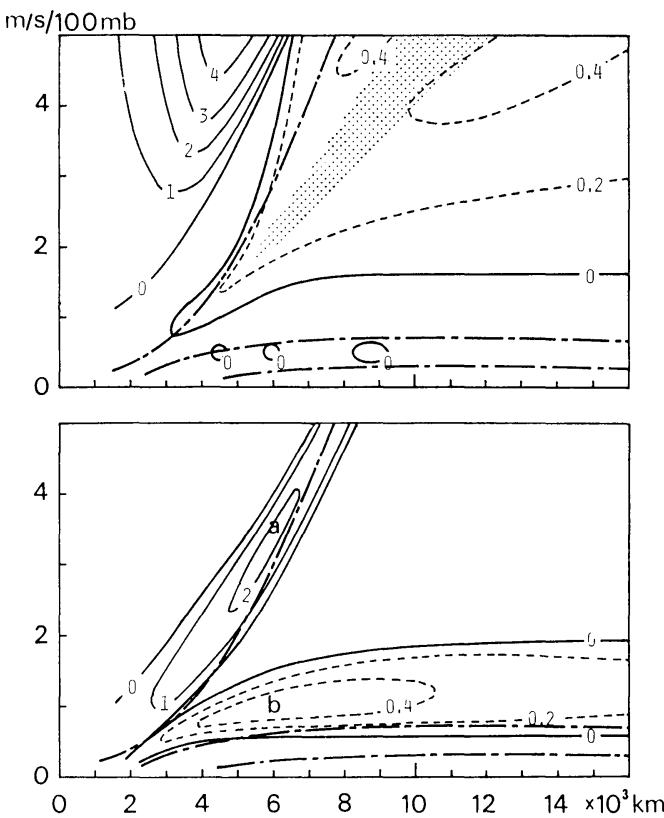

Fig. 14 Stability diagram in the 20-layer model $(h=1,000 \mathrm{~m})$. Top: Growth rate for the most unstable modified baroclinic instability. There exist two modes of modified baroclinic instability in the shaded area. Bottom: Growth rate for the topographic instability. Contour values are multiplied by $10^{2}$ and $\sigma_{r}=0.01$ corresponds to an $e$ folding time of 11.2 days. Dash-dotted lines denote the critical curves in case of no topography. 

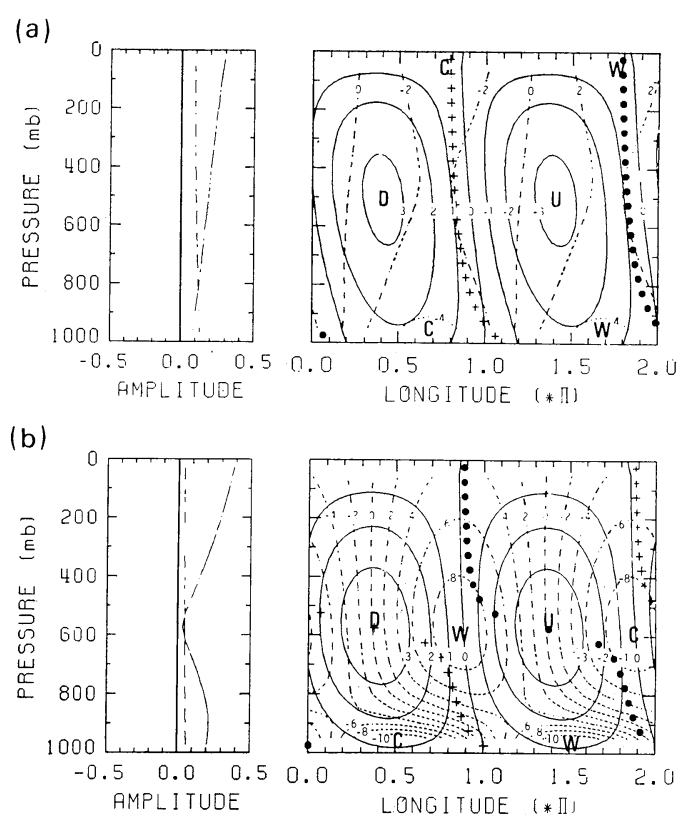

Fig. 15 Vertical structure of the perturbation in the topographic instability obtained in the 20-layer model $\left(L_{x}=6,000 \mathrm{~km}, h=\right.$ $1,000 \mathrm{~m}, \Lambda=3.5 \mathrm{~m} / \mathrm{s} / 100 \mathrm{mb}$ for (a) and $1 \mathrm{~m} / \mathrm{s} / 100 \mathrm{mb}$ for (b)). Left: Zonal component of the perturbation (broken line) and the amplitude of the wave perturbation of stream function (solid line). Right: Vertical structure of the wave perturbation. Trough and ridge lines are denoted by the symbols + and $\bullet$, respectively. The values $\omega$ multiplied by $10^{2}$ are contoured by solid lines and those of $\theta$ multiplied by 10 are contoured by broken lines.

the structure of both perturbations is notable. There are some minor differences: In the topographic instability, the westward tilt of the trough and ridge lines with height is small, the vertical velocity is large, and the amplitude of the temperature perturbation is large except for the lower layer in the second mode.

The time-variations of the perturbations in the modified baroclinic instability and in the neutral are essentially similar to those obtained in the 2-layer model, so that they are not shown here.

\section{Discussion}

Both of the modified baroclinic and the topographic instabilities obtained in the 2-layer model are qualitatively similar to those of the first mode in the 20-layer model. It is impossible to depict higher modes of instabilities in the 2-layer model because they have a nodal structure in vertical. The region of each instability does not overlap in the 2-layer model but it does in the 20-layer model. There also exist two modes of the modified baroclinic instability for the same vertical shear and wavelength.

As in the conventional baroclinic instability analysis (Hirota, 1968), the neutral waves corresponding to the Rossby wave were obtained in the 20-layer model as well as in the 2-layer model. The phase speed and the vertical structure of the neutral wave vary in time periodically depending on the phase difference between the wave and the topography (Fig. 11). This timedependent behavior of the neutral wave suggests the possible effect of the surface topography on the free (normal mode) oscillations in the real atmosphere.

In the previous two sections it was shown that the eddy perturbation energy is supplied by the baroclinic conversions $C\left(\overrightarrow{A Z}, A E^{\prime}\right)$ and $C$ $\left(A E^{\prime}, K E^{\prime}\right)$ for the instabilities of the Hadley solution. The energy conversion rate $C B\left(K Z^{\prime}\right.$, $\left.K E^{\prime}\right)$ is small and negative in the topographic instability. The surface topography plays a role of a sink of eddy kinetic energy. In this sense the term form-drag instability does not seem to be suitable for this instability.

However, other conversion terms in addition to those in Fig. 2 exist for the basic states with a stationary wave which are equilibrium solutions of (2-9). The linearized energy equations corresponding to $(2-27)-(2-32)$ have the energy conversion terms from the stationary wave of the basic states to the perturbation, $C\left(\overline{K E}, K E^{\prime}\right)$ and $C\left(\overline{A E}, A E^{\prime}\right)$. For the energy conversion rate from $A Z^{\prime}, C\left(A Z^{\prime}, A E^{\prime}\right)$ exists in addition to $C$ $\left(A Z^{\prime}, K Z^{\prime}\right)$ in $(2-31)$ and then the relation (3-3) for the topographic instability is not valid for the basic state with a stationary wave. Therefore the conversion term $C B\left(K Z^{\prime}, K E^{\prime}\right)$ by the topography may have a positive value: Formdrag by the topography becomes a possible energy source for the eddy perturbation.

From the above consideration it is found that the instability properties of the basic state with a stationary wave are not the same as those of the Hadley solution. Such an instability would correspond to the 'topographic instability' in the barotropic model (Charney and DeVore, 1979), in which the perturbation energy is supplied by the kinetic energy conversion from the basic stationary wave to the perturbation, $C\left(\overline{K E}, K E^{\prime}\right)$. 
The instability of the basic state including stationary planetary waves was first investigated by Matsuno and Hirota (1966) and Hirota (1967) for a simple barotropic case and recently extended by Frederiksen $(1978,1979)$. The presence of the planetary waves is found to produce regions of preferential development of the perturbations. However, he assumed that the planetary waves are not influenced explicitly by the surface topography and that the lower boundary condition is $w=0$. The perturbation is not affected by the surface topography which maintains the planetary waves. In the present loworder model, on the other hand, only the wave perturbation with the same scale as the topography is permitted. The instability of the wavy equilibrium in the low-order model would have a different property from the instability in the Frederiksen's model.

\section{Conclusion}

A stability analysis of a baroclinic zonal flow in the presence of the surface topography was performed by the use of the 2-layer and the 20-layer, quasi-geostrophic, low-order models. Two kinds of instabilities (the modified baroclinic and the topographic instabilities) are obtained in both models (Figs. 4 and 14). The second modes of both instabilities, in which the perturbation has a nodal structure in vertical, exist in the 20-layer model as in the conventional baroclinic stability analysis. The topographic instability arises in the neighborhood of the critical curves of the baroclinic instability with no topography, at which the wave perturbation becomes stationary.

There exists a distinct difference in the timevariations of perturbations between the two kinds of instabilities. In the modified baroclinic instability, the growth rate, the phase speed, and the vertical structure vary in time depending on the phase relation between the wave and the topography (Figs. 7 and 8). On the other hand, the wave perturbation grows exponentially in time without phase propagation in the topographic instability (Figs. 9 and 10).

Except for the time-dependency, however, the structure and the energetics are similar in both instabilities (Fig. 13). The eddy energy is supplied by the baroclinic conversion for any kind of instabilities of the Hadley solution. The conversion rate of the kinetic energy by the surface topography is small compared with the baroclinic conversion in all the unstable wavelengths.
As mentioned in the previous section, a stability analysis of a basic flow with a stationary wave in the presence of the surface topography is remained to future studies.

\section{Acknowledgments}

The authors would like to acknowledge the continuing guidance and encouragement of Professor I. Hirota of the Geophysical Institute, Kyoto University. The computations were performed with the use of the FACOM M-382 computer at the Data Processing Center of Kyoto University.

\section{Appendix A: Lower boundary condition}

From a kinematic condition, the lower boundary condition in the presence of the surface topography takes the form

$$
w(x, y, h, t)=u(x, y, h, t) \cdot \nabla_{H} h,
$$

where $w$ is the vertical velocity, $h(x, y)$ the height distribution of the topography, $u$ the horizontal velocity, and $\nabla_{H}$ the horizontal gradient operator. If the hydrostatic and the quasi-geostrophic approximations are permissible, the lower boundary condition (A-1) can be written in the pressure coordinate system as follows;

$$
\omega\left(x, y, p_{s}, t\right)=\frac{\partial p_{s}}{\partial t}-\rho_{s} g k \times \nabla_{P} \phi_{s} \cdot \nabla_{P} h,
$$

where $\omega$ is the vertical p-velocity, $\phi$ the geostrophic stream function, and the subscript $s$ denotes the surface value (at $z=h$ ). If we assume that the topography has a small amplitude $\left(p_{s}-p_{0} \ll p_{0}=1,000 \mathrm{mb}\right)$, we obtain an approximation of (A-2) which is identical to that in Charney and Straus (1980):

$$
\omega\left(x, y, p_{0}, t\right)=-\rho_{0} g k \times \nabla_{P} \psi_{0} \cdot \nabla_{P} h,
$$

where subscript 0 denotes the value at $p=p_{0}$.

From the analysis of energy equations it is shown that the topography does not make a net contribution to the time rate of change of the total energy $\left(\iint \phi_{0} \omega_{0} d x d y=0\right)$ under the approximated boundary condition (A-3). The finite difference form of (A-3) is given by (2-4), which is consistent with the energy constraint in the $N$-layer model.

\section{Appendix B: Nonlinear equations of the low-order model}

Full description of the nonlinear differential equations (2-9) is as follows; 


$$
\begin{aligned}
& (1+F) \dot{\phi}_{A^{1}}-F \dot{\phi}_{A}^{2}=-\alpha F\left(\phi_{K}^{1} \psi_{L}^{2}-\phi_{L}^{1} \phi_{K}^{2}\right) \\
& \left(n^{2}+1+F\right) \dot{\phi}_{K}{ }^{1}-F \dot{\psi}_{K}{ }^{2}=-\alpha n^{2} \phi_{A}{ }^{1} \phi_{L}{ }^{1}+\alpha F\left(\phi_{A}{ }^{1} \phi_{L}{ }^{2}-\phi_{L}{ }^{1} \phi_{A}{ }^{2}\right)+\beta n \psi_{L}{ }^{1} \\
& \left(n^{2}+1+F\right) \dot{\phi}_{L}{ }^{1}-F \dot{\psi}_{L}{ }^{2}=\alpha n^{2} \phi_{A}{ }^{1} \psi_{K}{ }^{1}-\alpha F\left(\phi_{A}{ }^{1}{\phi_{K}}^{2}-\phi_{K}{ }^{1} \phi_{A}{ }^{2}\right)-\beta n \psi_{K}{ }^{1} \\
& (1+2 F) \dot{\phi}_{A}^{l}-F\left(\dot{\phi}_{A}^{l+1}+\dot{\phi}_{A}^{l-1}\right)=-\alpha F\left[\phi_{K}^{l}\left(\phi_{L}^{l+1}+\phi_{L}^{l-1}\right)-\phi_{L}^{l}\left(\phi_{K}^{l+1}+\phi_{K}^{l-1}\right)\right] \\
& \left(n^{2}+1+2 F\right) \dot{\phi}_{K}^{l}-F\left(\dot{\phi}_{K}^{l+1}+\dot{\phi}_{K}^{l-1}\right)=-\alpha n^{2} \phi_{A}^{l} \phi_{L}^{l}+\alpha F\left[\phi_{A}^{l}\left(\phi_{L}^{l+1}+\phi_{L}^{l-1}\right)\right. \\
& \left.-\phi_{L}^{l}\left(\phi_{A}^{l+1}+\phi_{A}^{l-1}\right)\right]+\beta n \psi_{L}^{l} \\
& \left(n^{2}+1+2 F\right) \dot{\phi}_{L}^{l}-F\left(\dot{\phi}_{L}^{l+1}+\dot{\phi}_{L}^{l-1}\right)=\alpha n^{2} \phi_{A}^{l} \psi_{K}^{l}-\alpha F\left[\phi_{A}^{l}\left(\phi_{K}^{l+1}+\phi_{K}^{l-1}\right)\right. \\
& \left.-\phi_{K}{ }^{l}\left(\phi_{A}^{l+1}+\psi_{A}^{l-1}\right)\right]-\beta n \psi_{K}^{l} \\
& (l=2,3, \cdots, N-1) \\
& (1+F) \dot{\phi}_{A}^{N}-F \dot{\phi}_{A}^{N-1}=-\alpha F\left(\phi_{K}^{N} \psi_{L^{N-1}}-\phi_{L}^{N} \phi_{K^{N-1}}\right)-\alpha\left(\phi_{K}^{N} h_{L}-\phi_{L}{ }^{N} h_{K}\right) \\
& \left(n^{2}+1+F\right) \dot{\phi}_{K}^{N}-F \dot{\phi}_{K^{N-1}}=-\alpha n^{2} \psi_{A^{N}} \psi_{L}^{N}+\alpha F\left(\psi_{A^{N}} \psi_{L}^{N-1}-\phi_{L}^{N} \psi_{A}^{N-1}\right)+\beta n \psi_{L}^{N} \\
& +\alpha\left(\psi_{A^{N}} h_{L}-\psi_{L}{ }^{N} h_{A}\right) \\
& \left(n^{2}+1+F\right) \dot{\phi}_{L}^{N}-F \dot{\phi}_{L}^{N-1}=\alpha n^{2} \phi_{A}^{N} \phi_{K}^{N}-\alpha F\left(\phi_{A^{N}} \phi_{K}^{N-1}-\phi_{K}^{N} \phi_{A}^{N-1}\right)-\beta n \psi_{K}^{N} \\
& -\alpha\left(\psi_{A^{N}} h_{K}-\psi_{K^{N}} h_{A}\right)
\end{aligned}
$$

where

$$
\alpha=-\iint F_{A} J\left(F_{K}, F_{L}\right) d x d y=8 \sqrt{2} n / 3 \pi
$$

and $F=1 / S$.

\section{Appendix C: Definition of energy conversion}

The energy conversion terms on the right hand side of the linearized energy equations (2-28)(2-32) are defined as follows;

$$
\begin{aligned}
& C\left(A Z^{*}, K Z^{*}\right) \\
& =2 G f_{0} \sum_{l=1}^{N-1}\left(\bar{\psi}_{A}^{l+1}-\bar{\psi}_{A}{ }^{l}\right) \omega^{\prime}{ }_{A}^{l+1 / 2}, \\
& C\left(A Z^{\prime}, K Z^{\prime}\right) \\
& =2 G f_{0} \sum_{l=1}^{N-1}\left(\psi^{\prime}{ }_{A}^{l+1}-{\psi^{\prime}}^{\prime}{ }^{l}\right) \omega^{\prime}{ }_{A}^{l+1 / 2}, \\
& C\left(\overline{A Z}, A E^{\prime}\right) \\
& =\frac{2 G f_{0} \alpha}{S} \sum_{l=1}^{N-1}\left(\bar{\psi}_{A}^{l+1}-\bar{\psi}_{A}^{l}\right) \\
& \times\left(\psi^{\prime}{ }_{K}{ }^{l+1} \psi^{\prime}{ }^{l}{ }^{l}-\phi^{\prime}{ }^{l}{ }^{l} \psi^{\prime}{ }^{l+1}\right), \\
& =2 G f_{0} \sum_{l=1}^{N-1}\left\{\left({\psi^{\prime}}^{\prime}{ }^{l+1}-{\phi^{\prime}}^{\prime}{ }^{l}\right) \omega^{\prime}{ }_{K}^{l+1 / 2}\right. \\
& \left.+\left({\psi^{\prime}}_{L^{l+1}}-{\psi^{\prime}}_{L^{l}}{ }^{l}\right) \omega^{\prime}{ }^{l+1 / 2}\right\}, \\
& =-2 G f_{0}\left(\psi^{\prime} K^{N} \omega^{\prime}{ }^{N+1 / 2}+{\psi^{\prime}}^{\prime}{ }^{N} \omega^{\prime}{ }^{N+1 / 2}\right) \\
& =2 G f_{0} \alpha \psi^{\prime}{ }_{A}^{N}\left(\psi^{\prime}{ }^{N} h_{L}-\psi^{\prime}{ }^{N} h_{K}\right),
\end{aligned}
$$

$$
\begin{gathered}
-\frac{\alpha}{S}\left(\bar{\psi}_{A}{ }^{l}{\psi^{\prime}}^{\prime}{ }^{l+1}-{\psi^{\prime}}{ }^{l} \bar{\psi}_{A}{ }^{l+1}\right), \\
\omega^{\prime}{ }_{L}^{l+1 / 2}=-\frac{1}{S} \frac{d}{d t}\left({\phi^{\prime}}_{L^{l+1}}{ }^{l+1}{\phi^{\prime}}_{L}{ }^{l}\right) \\
-\frac{\alpha}{S}\left(\bar{\psi}_{A}{ }^{l}{\psi^{\prime}}^{\prime}{ }^{l+1}-{\phi^{\prime}}^{\prime}{ }^{l} \bar{\psi}_{A}{ }^{l+1}\right), \\
(l=1,2, \cdots, N-1)
\end{gathered}
$$

and the scaling factor

$$
G=L^{2} f_{0}{ }^{2} \Delta p /(2 g) \text {. }
$$

\section{References}

Charney, J. G., 1947: The dynamics of long waves in a baroclinic westerly current. J. Meteor., 4, $135-162$.

- and J. G. DeVore, 1979: Multiple flow equilibria in the atmosphere and blocking. $J$. Atmos. Sci., 36, 1205-1216.

- and D. M. Straus, 1980: Form-drag instability, multiple equilibria and propagating planetary waves in baroclinic, orographically forced, planetary wave systems. J. Atmos. Sci., 37, 1157-1176.

Eady, E. T., 1949: Long waves and cyclone waves. Tellus, 1, 33-52.

Frederiksen, J. S., 1978: Instability of planetary waves and zonal flows in two-layer models on a sphere. Quart. J.R. Met. Soc., 104, 841-872.

where

$$
\begin{aligned}
& \omega^{\prime}{ }_{A}^{l+1 / 2}=-\frac{1}{S} \frac{d}{d t}\left({\psi^{\prime}}^{\prime}{ }^{l+1}-{\psi^{\prime}}^{\prime}{ }^{l}\right), \\
& \omega^{\prime}{ }^{l+1 / 2}=-\frac{1}{S} \frac{d}{d t}\left({\psi^{\prime}}^{l}{ }^{l+1}-{\psi^{\prime}}^{\prime}{ }^{l}\right)
\end{aligned}
$$
, 1979: Baroclinic instability of zonal flows and planetary waves in multi-level models on a sphere. J. Atmos. Sci., 36, 2320-2335.

Green, J. S. A., 1960: A problem in baroclinic stability. Quart. J.R. Met. Soc., 86, 237-251.

Hirota, I., 1967: Dynamic instability of the stratospheric polar vortex. J. Meteor. Soc. Japan, 45, $409-421$.

— 1968: On the dynamics of long and ultra- 
long waves in a baroclinic zonal current. J. Roads, J. O., 1982: Stable and unstable near-resoMeteor. Soc. Japan, 46, 234-249.

Matsuno, T. and I. Hirota, 1966: On the dynamical stability of polar vortex in wintertime. J. Meteor. Soc. Japan, 44, 122-128.

Pedlosky, J., 1981: Resonant topographic waves in barotropic and baroclinic flows. J. Atmos. Sci., 38, 2626-2641. nant states in multilevel, severely truncated, quasi-geostrophic models. J. Atmos. Sci., 39, 203-224.

Yoden, S., 1983: Nonlinear interactions in a twolayer, quasi-geostrophic, low-order model with topography. Part I: Zonal flow-forced wave interactions. J. Meteor. Soc. Japan, 61, 1-18.

\title{
表面地形がある場合の傾圧帯状流の不安定性
}

\author{
余 田 成 男・向 川均 \\ 京都大学理学部地球物理学教室
}

2 層および20層の準地衡風近似をした低次モデルを用いて, 表面地形がある場合の傾圧帯状流の不安定性を調 ベた。このモデルは従来の傾圧不安定理論と比べて，(1)地形の効果を含む，(2)帯状成分の摂動を考える，という 相違点がある。

定常波動解を含まない平均流（ハドレー解）に関して，線型化固有值問題を解くことにより，次の 2 種類の不 安定性が得られた。1つは地形の影響をうけた傾圧不安定である。波動擾乱の発達率，位相速度拉よび鉛直構造 は，時間とともに変化する。それは，それらが波と地形の位相関係に依存しているからである。もら1つは地形 性不安定と呼ばれるもので, 波動擾乱は指数関数的に増大する。ただし, 波の位相は地形に対して一定のままで ある。

20層モデルでは，2 層モデルで得られる不安定に対応する第 1 モードの不安定に加えて，鉛直に節目をもつ構 造の第 2 モードの不安定が得られた。

時間依存性は別にして，両方の不安定性はエネルギー的に類似している。両者ともに波動擾乱のエネルギーは， 基本場である带状流の有効位置エネルギーからの変換によって供給されている。表面地形による運動エネルギー の変換はこれに比べて小さい。

一方，定常波動解を含む基本場の安定性を考えると，波動擾乱のエネルギーは，基本場の定常波からのエネル ギーによって供給される可能性がある。従って，ハドレー解の安定性とは異なる。 